\title{
SOLVING SELECTED QUALITY MANAGEMENT PROBLEMS WITH THE USE OF THE D4 DISCIPLINE ALGORITHM OF THE G8D METHOD \\ doi: $\quad 10.2478 /$ czoto-2019-0126
}

Date of submission of the article to the Editor: $12 / 12 / 2018$

Date of acceptance of the article by the Editor: 28/01/2019

\author{
Joanna Cyganiuk ${ }^{1}$ - orcid id: 0000-0002-7279-0692 \\ Piotr Kuryło, prof. UZ ${ }^{1}$ - orcid id: 0000-0001-9820-1254 \\ Adam Idzikowski ${ }^{2}$ - orcid id: 0000-0003-1178-8721 \\ Siegmund Fröhlich ${ }^{3}$ \\ Przemysław Niemira ${ }^{1}$ \\ ${ }^{1}$ University of Zielona Gora, Poland \\ ${ }^{2}$ Czestochowa University of Technology, Poland, adam.idzikowski@wz.pcz.pl \\ ${ }^{3}$ Hochschule Emden/Leer, Germany
}

\section{Abstract:}

The G8D method is one of the methods used in quality management using quality management tools and designed to solve problems occurring in production processes. The method consists of 8 disciplines and ensures the required quality of both production processes and finished products. It may also be applied to the optimization of production processes, while ensuring their safety.

In the article, the authors presented the method of using the D4 discipline algorithm of the G8D method allowing to detect the root cause of the problem in the process and to indicate the so-called escape point. The authors presented the course of action for discipline D4 undertaken when the root cause of the problem is to be analysed. The procedure is presented on an exemplary process of the projection welding of a nut.

Keywords: the G8D method, root cause, escape point, quality management, production process, safety

\section{INTRODUCTION}

The Global 8 Disciplines (G8D) method is a method designed to detect and correct problems and deviations mainly in production processes (Celmerowski, 2007; Global 8D solving workbook, 2018; Grecu et al., 2015) although currently it is also used in design, warehousing, logistics or even in accounting. The method allows to ensure not only the proper course of production processes, but also increases the safety of production of products in accordance with the specification.

The G8D is a method implemented in an enterprise when defects are detected(Grecu et al., 2015). These defects are most often reported by the customer (Sarkarand Rajagopalan, 2018) and this applies mainly to faulty products (factory rejects). 
However, after the report from the customer, it also often turns out that the next batch of products to be shipped also contains these factory rejects.

G8D is a methodology that requires the work of a group of experts from all areas that the detected defect is related to. In the case of production processes with detected problems, the group may include: the area leader, process engineer, quality engineer. If necessary, other specialists may also be invited to participate in the work of such a group. This group is responsible for identifying the problem, indicating the place where the problem is generated, and for repair work aimed at eliminating the weak link contributing to the production of products that do not conform the construction and lor technological specifications. This group is also responsible for repairing or optimizing the identified processes that contribute to the production of factory rejects. The main decisions regarding the method of the repair and optimization of the process with a detected defect, is always taken by the G8D group champion, having regard for the well-being of the company and not exposing it to excessive financial expenses (Celmerowski, 2007).

\section{THE ALGORITHM OF PROCEDURE IN DISCIPLE D4 OF THE G8D METHOD}

Discipline D4, i.e. the fourth discipline of the G8D, follows discipline D3, in which the effects of problems in an external or internal client are isolated.

Discipline D4 has two main functions, which include the "root cause" and "escape point" for the processes where the defective product is created. The "root cause" should be understood as a verified, single reason for the inconsistencies. Sometimes a situation may arise where the G8D group cannot determine the single root cause. In this case, the group of root causes should be minimized. The causes that have been shortlisted as significant should be considered as "root causes". The escape point is the control point in the production process that is the closest to the root cause where the defect (problem which should have been detected, had not been detected) originated (Global 8 D solving workbook, 2018).

D4 is intended to isolate the root cause and the escape point from the process and to verify them. Isolation and verification of the root cause requires verification of all possible causes taking into account the "description of the problem" that is formulated in discipline D2. As for the escape point, it means isolating and verifying the place in the production process where the effect of the root cause (e.g. the product defect) failed to be detected.

If the analysis performed in discipline D4 showed more than one potential root cause, which the G8D team considered important, then none of them should be rejected. Each of these root causes must be transferred to the next stages of the G8D.

The exemplary tools supporting discipline D4 include (Celmerowski, 2007; Ramachandran et all, 2013):

- 5xWhy,

- Ishikawa diagram,

- Pareto diagram,

- analysis Is/ls Not,

- FMEA,

In addition to the above tools, it is also worth using the reports on factory rejects and conducting "interviews" with the leaders (or operators) of the areas where the root 
cause is sought. The G8D group can also use the so-called brainstorming method at this stage.

Going step by step through the D4 discipline, it is worth using the algorithm (diagram) shown in Figures 1, 2 and 3.

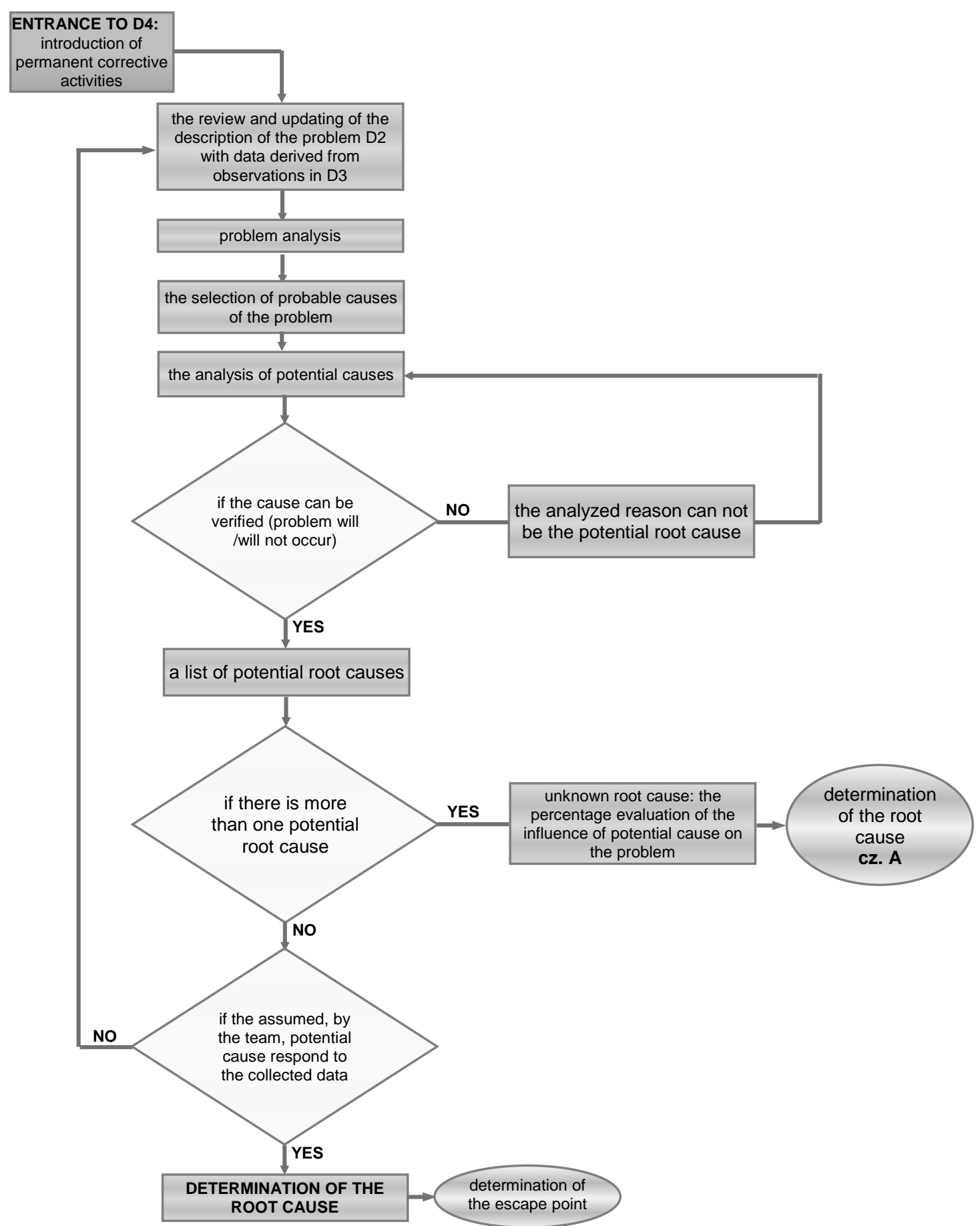

Fig. 1. The algorithm of proceeding in discipline D4 (flowchart) - the definition of a single "root cause" [elaboration based on (Global 8 D solving workbook, 2018)]

The D4 discipline algorithm consists of three parts: an algorithm for a single root cause, an algorithm for several root causes, and an algorithm for an escape point. Figure 1 shows the first part of the algorithm that allows to determine one potential 
root cause. In Figure 2, the further part of the root cause determination algorithm is presented for the case where there are several potential sources, and it is required to determine their percentage contribution to the defect occurrence.

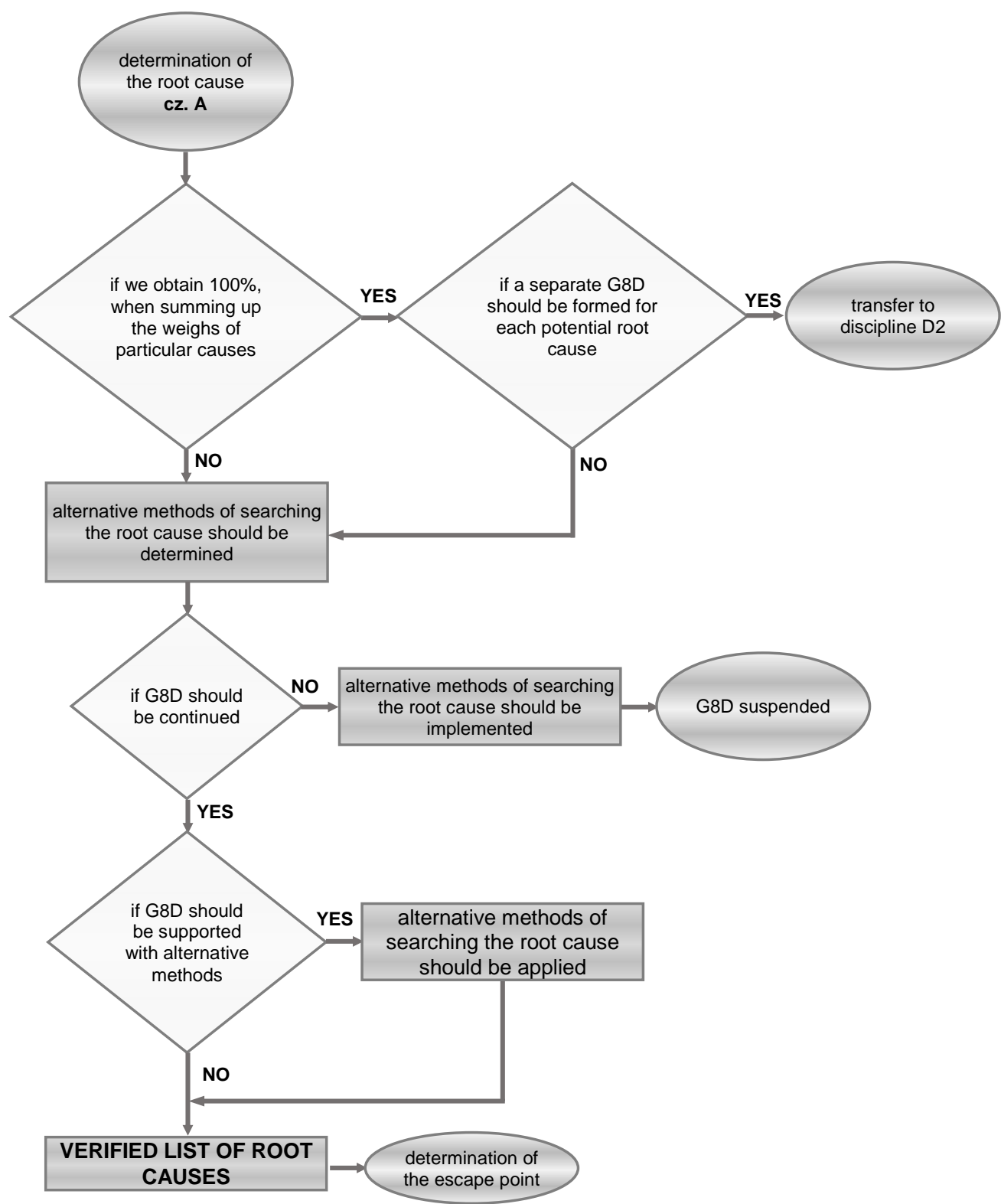

Fig. 2. The algorithm of conduct in discipline D4 (flowchart) - defining the list of "root causes" [elaboration based on (Global 8 D solving workbook, 2018)]

The detection of the root cause always starts with updating all of the data, collected in discipline D2, by additional information that the G8D group collected during the implementation of the temporary corrective actions in discipline D3. Then the problem is analysed and the probable causes of the problem are indicated. Probable causes are also analysed by the G8D team. The first analysis concerns the answer to the question whether the probable root causes could have triggered the problem that the G8D group deals with. A negative answer to this question enforces a further search for the root causes. The positive answer enforces drawing up a list of selected potential root causes, and additionally it is important to determine if the defect was 
generated by a single cause of a number of causes. If there are more causes, then the algorithm shown in Figure 2 should be applied.

If the problem is due to single cause, it should be examined whether this cause is responsible for all the problems described in discipline D2. If the answer is yes, the G8D team succeeded in finding the "root cause" and proceeds to determine the escape point.

In the case of several root causes generating the problem (and none of them has been rejected in the analysis) the algorithm shown in Figure 2 applies. The first analysis is whether the sum of selected potential root causes gives the total of $100 \%$, after adding their partial percentage values. If so, a separate G8D should be established for each of the root causes, in each case starting the process with discipline D2. If not, alternative methods for determining the causes are suggested, however, it should be considered whether to continue G8D for the analysed problem or to suspend the G8D team's work. In the event that the team decides to continue working on the problem and does not decide to support the analysis with additional alternative methods, a verified list of root causes is drafted and the analysis of the escape point is commenced.

For cases presented in Figure 1 and Figure 2, the algorithm of procedure for detecting the escape point is shown in Figure 3

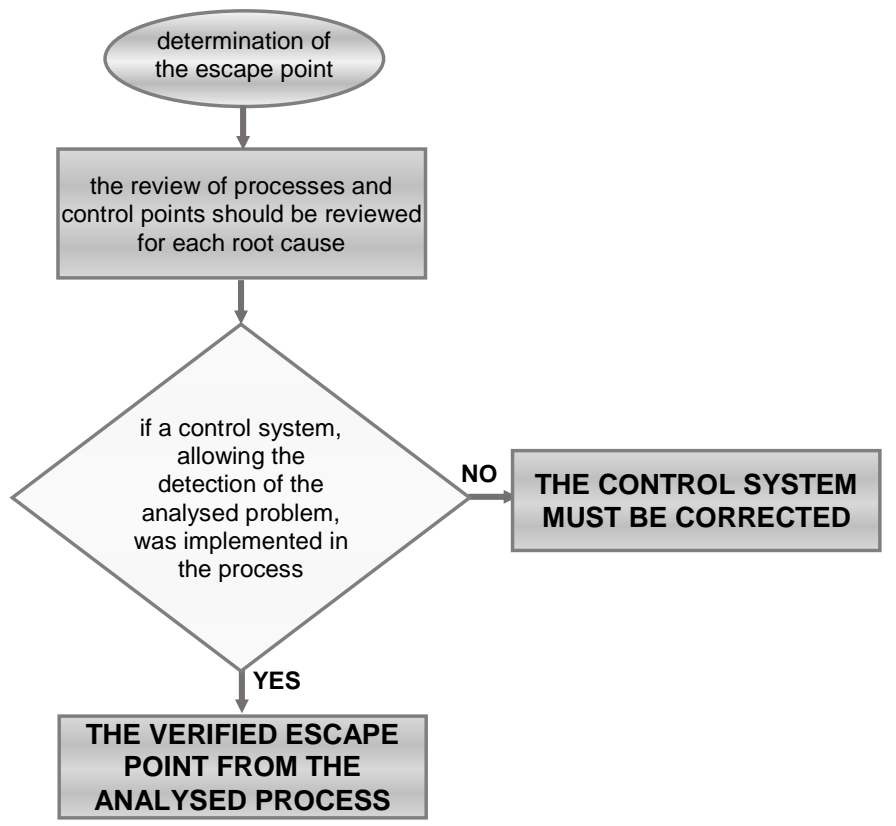

Fig. 3. The algorithm of procedure in discipline D4 (flowchart) - the "escape point" determination [elaboration based on (Global 8 D solving workbook, 2018)]

The determination of the escape point requires analysing the production process and verifying the correct operation of control points in the process. The verification is carried out for each root cause. The verification is an analysis of the monitoring system capabilities in terms of the correct detection of a defect / error of the product that has been reported by the customer. If the monitoring system has failed, then it is the cause for the defective product to be classified as compliant with the specification. Such a monitoring system must be modified and its operation verified. If the control system detects a faulty item, then we get a verified escape point. 


\section{APPLICATION OF D4 DISCIPLINE FOR A CASE OF A MISSING NUT}

The application of the algorithm of discipline D4 is presented on the example of a missing nut (M8x16). The nut should have been welded to the formed sheet (drawing), The problem of a missing nut was reported by the client experiencing the symptom.

Finding a technical "root cause" requires the G8D team to thoroughly analyse and trace the process where the defect occurred.

During the analysis carried out in the D2 and D3 disciplines, the G8D team pointed to the projection welding process as the source of the problem. The projection welding machine was identified as a defect generating point.

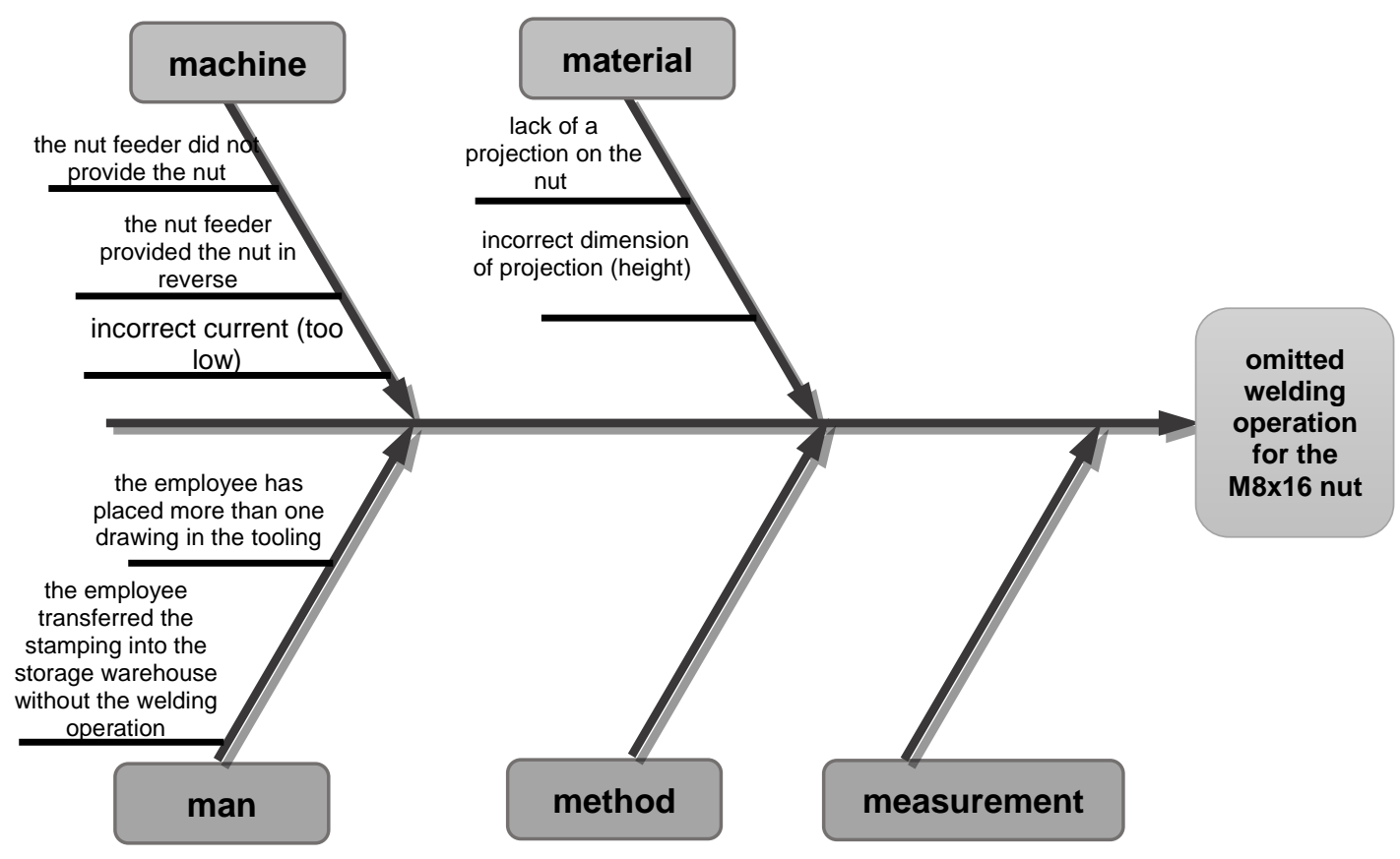

Fig. 4. Ishikawa diagram for potential root causes - Discipline D4

Based on the process data and the knowledge of its procedure, the G8D group, using the brainstorming method and the Ishikawa diagram (Figure 4), chose potential source reasons. Seven possible root causes were identified which could have resulted in the production of a product not compliant with the technical specification, and thus generating a problem reported by the customer.

Using the D4 discipline algorithm, each of the six causes had to be verified. Potential root causes and their verifications are presented in Table 1.

After analysing the facts confirming or denying the existence of causes mentioned in the Ishikawa diagram, all except for problem 4 were excluded (an employee placed more than one extrude in the machine).

Observation of the employee's activities during the welding process showed that the drawing placed on top of each other during the welding process gave the same defective product as the one sent to the customer. The process was not protected against this type of possibility - the escape source for root causes no. 4 was thus found (in the process there is no method preventing the two extrusions from being placed at the same time at the welding station). 
Table 1

Potential causes of defects of the finished product with the technical specification

\begin{tabular}{|c|c|c|}
\hline potential cause & confirmation & denial \\
\hline $\begin{array}{l}\text { 1. the feeder failed to } \\
\text { feed the nut }\end{array}$ & - no confirmation & $\begin{array}{l}\text { - the gravitational feeder is equipped } \\
\text { with a mechanical separator and a } \\
\text { sensor which detects the nut in the } \\
\text { separator; a signal from the sensor } \\
\text { allows starting the machine } \\
\text { - inspection reports showed no } \\
\text { malfunction in the sensor and } \\
\text { separator operation }\end{array}$ \\
\hline $\begin{array}{l}\text { 2. the nut feeder } \\
\text { provided a nut in } \\
\text { reverse }\end{array}$ & - no confirmation & $\begin{array}{l}\text { - no signs of welding on the faulty } \\
\text { product, }\end{array}$ \\
\hline $\begin{array}{l}\text { 3. incorrect current } \\
\text { (too low) }\end{array}$ & - no confirmation & $\begin{array}{l}\text { - no traces of welding on the faulty } \\
\text { product }\end{array}$ \\
\hline $\begin{array}{l}\text { 4. an employee } \\
\text { placed more than } \\
\text { one extrude in the } \\
\text { machine }\end{array}$ & $\begin{array}{l}\text { - two extrudes may be placed } \\
\text { in the machine } \\
\text { - the performed experiments } \\
\text { consisting in welding the nut } \\
\text { to the second sheet } \\
\text { underneath revealed that } \\
\text { the singes of burns } \\
\text { occurring in defective details } \\
\text { were identical to the ones in } \\
\text { the experiments }\end{array}$ & - no denial \\
\hline $\begin{array}{l}\text { 5. welding operation } \\
\text { omitted; the employee } \\
\text { placed the extrude } \\
\text { without a nut to the } \\
\text { storage without the } \\
\text { welding }\end{array}$ & - no confirmation & $\begin{array}{l}\text { - the storage is equipped with a } \\
\text { pneumatic sensor detecting the nut }\end{array}$ \\
\hline $\begin{array}{l}\text { 6. no projection on } \\
\text { the nut }\end{array}$ & - no confirmation & $\begin{array}{l}\text { the inspection of the supplied caps } \\
\text { did not show any inconsistencies } \\
\text { with their technical specifications }\end{array}$ \\
\hline $\begin{array}{l}\text { 7. incorrect } \\
\text { projection dimensions } \\
\text { (height) }\end{array}$ & - no confirmation & $\begin{array}{l}\text { the inspection of the supplied caps } \\
\text { did not show non-compliance with } \\
\text { their technical specifications }\end{array}$ \\
\hline
\end{tabular}

\section{CONCLUSION}

The correct proceeding of the D4 discipline requires the G8D members to have extensive knowledge about the processes, their procedures and equipment used. It also requires the capacity to predict possible employees' behaviours that could lead to production of defective products.

Discipline D4 is a labour-intensive discipline, especially when there are many root causes. The principle of this discipline is that none of the potential root causes can be omitted in the analysis, so often the G8D team has to face a difficult and extensive task to do.

This discipline enables showing weaknesses in the production process and sometimes suggesting corrective actions and recommendations to be implemented in 
further disciplines (if we know where is the reason of the problem), which often significantly streamlines the production process and supports employees during their activities.

\section{REFERENCES}

Allur, E., Heras-Saizarbitoria, I., Boiral, O., Testa, F., 2018. Quality and Environmental Management linkage: A review of the literature. Sustainability, Switzerland, $10,11,4311$.

Celmerowski, Z., 2007. Metoda Global 8D. Kraków: TQM soft.

Company reserved materials., 2011.

Company reserved materials., 2012.

Czarski, A., 2010. Statystyczne Sterowanie Procesem - Szkolenie Podstawowe. Kraków: TQM soft.

Dan, M., Filip, A., Popescu, S., 2016. Mistakes in the application of 8d methodology and their impact on customer satisfaction in the automotive industry. IRUM 2016 International Conference On Production Research - Regional Conference Africa, Europe And The Middle East (ICPR-AEM 2016) and 4TH International Conference On Quality And Innovation In Engineering And Management (QIEM 2016), 297302

Global 8D solving workbook, 2018. Results People developing people. Essex

http://cdn2.hubspot.net/hub/170850/file-18472412-pdf/docs/global_8d_workbook.pdf (access 1 November 2018)

Grecu, I., Belu, N., Misztal, A., 2015. Increasing customer satisfaction through the application of the $8 d$ methodology. Management - the key driver for creating value

Book Series: International Conference of Management and Industrial Engineering, 488-495.

ISO., 2015. Quality Management Principles. Geneva: The International Organization for Standardization, Available online:

https://www.iso.org/files/live/sites/isoorg/files/archive/pdf/en/pub100080.pdf (accessed on 1 November 2018).

Majerník, M., Štofová, L., Bosák, M., Szaryszová, P. , 2016. Process innovations and quality measurement in automotive manufacturing. Production Management and Engineering Sciences - Scientific Publication of the International Conference on Engineering Science and Production Management, ESPM 2015, 179-184.

Ramachandran, T., Prakash, R., Karthik, R., Valappa, Kumar S., 20013. An application of $g 8 D$ methodology as a problem solving tool in a manufacturing firm. International Conference of Sustainable Manufacturing and Operations Management ISOM. Conference Materials, Gyandhara International, 331-335

Rambaud, L., 2006. 8D Structured Problem Solving: A Guide to Creating High Quality $8 D$ Reports. PHRED Solutions.

Sarkar, S., Rajagopalan, B., 2018. Consumer safety complaints and organizational learning: evidence from the automotive industry. International Journal of Quality and Reliability Management, 35(10), 2094-2118.

Tague, N., R., 2004. Seven Basic Quality Tools. American Society for Quality: Milwaukee, Wisconsin, USA.

Zymonik, Z., Hamrol, A., Grudowski, P. 2013. Zarządzanie jakością i bezpieczeństwem. PWE, Warszawa 